\title{
A propósito de libros electrónicos
}

\author{
Por Lluís Anglada
}

\begin{abstract}
Resumen: El autor comenta algunos aspectos de los libros electrónicos: ergonomía, modelos de mercado, idiomas, etc., que explican por qué todavía falta para que tengan amplia aceptación.

Palabras clave: Libros electrónicos, Libro-e, Características, Mercado, Estrategias, Ergonomía, Idiomas.

\section{Title: About e-books}

Abstract: The author comments on some aspects of electronic books: ergonomics, market models, languages, etc., which explain why there is still time for e-books to reach a wide acceptance.
\end{abstract}

Keywords: Electronic books, eBooks, Features, Market Strategies, Ergonomics, Languages

Anglada, Lluís. “A propósito de libros electrónicos”. En: El profesional de la información, 2008, julio-agosto, v. 17, n. 4, pp. 414-415.

DOI: 10.3145/epi.2008.jul.07

\section{Libros}

NO PODEMOS HABLAR DE LIBROS-E SIN MÁS. Como no podemos hacerlo de revistase. Bajo este nombre (el de revistas) distinguimos entre boletines, hojas informativas, periódicos, revistas-magazines, revistas-journals... Y para cada subgrupo la digitalización de las revistas ha tenido y está teniendo una trayectoria propia.

El gran éxito en revistas digitales ha estado en el sector de las revistas científicas o journals. Un $50 \%$ de las revistas de este subgrupo están en digital y esto se debe a varios factores entre los cuales destaco dos que han contribuido decisivamente:

1. La concentración de títulos en grandes grupos editoriales, $\mathrm{y}$

2. La compra consorciada de paquetes de revistas.

Hay muchos tipos de libros: manuales, obras de referencia, estudios universitarios, libros de texto, obras de divulgación... De momento ningún subgrupo destaca por tener porcentajes elevados de digitalización. Quizá el más alto sea el formado por las obras de referencia, pero incluso en éste el libro-e no está teniendo una presencia mayoritaria. ¿Quiere decir esto que el libro-e no tiene futuro? De ninguna manera, pero sí que su futuro en lo concreto es incierto.

\section{Ergonomía}

Siempre que se ha hablado (inteligentemente) de los libros se ha comentado lo enormemente ergonómicos que son. De fácil lectura, transportables, anotables... El éxito de las revistas-e (de los journals) está en buena parte en lo leíbles que son los artículos que publican una vez nos los hemos impreso (como antes hacíamos una vez nos los habíamos fotocopiado). No es fácil conseguir lo mismo con los libros-e. Dejando al margen algunos tipos (las obras de referencia y los manuales universitarios, quizá), el éxito dependerá de que se estabilice algún instrumento de lectura transportable para los libros-e. De momento no hay un formato estándar que permita la descarga en cual- quiera de los múltiples lectores (de diferentes prestaciones y precios) desarrollados por un sinfín de fabricantes en competencia.

\section{Modelo de precio}

No hay innovación sin tecnología pero tampoco sin necesidad social ni modelo de negocio para la misma. El éxito de las revistas científicas-e ha venido en parte por tener un modelo de precio que no por criticado ha dejado de ser válido y que se ha extendido con gran rapidez. El mercado de las revistas-e nació y se consolidó con un modelo de precio basado en 3 elementos: un uso colectivo de las revistas-e suscritas, un precio basado en lo pagado por las revistas en papel con un incremento del 10-15\% dependiendo de los casos, y, como valor añadido, se reciben las revistas previamente suscritas y muchas más. No vemos de momento que los diversos modelos de precio de los editores de libros-e presenten ninguna característica que los haga sumamente atractivos. Uso colectivo, sí, pero pagando en función del colectivo servido; precios parecidos a los del 
